\title{
Auditoria de obra pública
}

\section{Audit of public work}

\author{
Valtencir Godinho de Camargo ${ }^{1}$
}

\section{Resumo}

As obras públicas municipais, principalmente as reformas e pequenas construções, com mobilização de mão-de-obra em até 20 funcionários, onde não é obrigatória a elaboração do PCMAT (Programa de Condições e Meio Ambiente de Trabalho na Indústria da Construção Civil), são realizadas sem atender as normas regulamentadoras, onde são motivados pela deficiência na elaboração do orçamento, do edital de licitação, contrato e fiscalização. O desconhecimento especializado na área da Engenharia de Segurança do Trabalho soma aos fatores que levam o órgão público assumir riscos desnecessários, como a responsabilidade objetiva nos encargos trabalhistas e indenizações por doenças, acidentes ou mortes. Este artigo tem por finalidade de indicar as diretrizes para que o programa de saúde e segurança do trabalho seja efetivamente aplicado nas obras públicas.

Palavras-chave: Auditoria de obra pública. Segurança do trabalho em obra pública. PCMAT.

\begin{abstract}
The municipal public works, especially the reform and small constructions, with mobilization of manpower with up to 20 employees, where it is not mandatory elaboration of Program Conditions and Work Environment in the Construction Industry, are conducted without meeting the regulatory norm, which are motivated by the deficiency in the elaboration of the budget, the bidding documents, in the contract and supervision. The unfamiliarity specialized in the area of the Engineering of Safety of the Work adds to the factors that lead the public agency take unnecessary risks, as the objective responsibility, the labor charges and indemnities for illnesses, accidents or deaths. This article aims to indicate the guidelines for the program to health and safety is applied effectively in public works.

Key words: Audit of Public Works. Safety in public works. Program conditions and work environment in the construction industry.
\end{abstract}

\section{Introdução}

A construção civil continua contribuindo muito para o alto índice de acidentes do trabalho e doenças ocupacionais, gerando grandes prejuízos à nação através dos custos assumidos pelo INSS, que está trabalhando para que esses custos sejam direcionados para as empresas.

Constatado pelo INSS que a empresa tem a sua responsabilidade pelo acidente ou doença ocupacional, o ressarcimento dos valores gastos com o benefício é solicitado com base na Lei 8.213/91, artigo 120 (Nos casos de negligência quanto às normas padrão de segurança e higiene do trabalho indicados para a proteção individual e coletiva, a Previdência Social proporá ação regressiva contra os responsáveis.), de modo judicial através da Procuradoria Federal, onde caberá também ao órgão público pela responsabilidade solidária.

O Ministério do Trabalho em conjunto com os escritórios regionais, e com a instalação da comissão tripartite para acompanhar o Programa Boas Práticas de Segurança e Saúde do Trabalho, vem atuando de

\footnotetext{
1 Gestor de Engenharia na Prefeitura Municipal de Londrina- PR; valtencir.camargo@londrina.pr.gov.br
} 
maneira que as empresas tenham que trabalhar para diminuir as doenças ocupacionais e os acidentes de trabalho.

Outra medida que surge com a tentativa de forçar as empresas a reduzirem os acidentes e doenças ocupacionais é a readequação dos valores do FAP (fator de Acidentário de Prevenção) que, com o acréscimo dos acidentes, a porcentagem da alíquota aumentará proporcionalmente.

Mesmo neste contexto, as obras públicas do âmbito municipal são realizadas normalmente sem os mínimos cuidados quanto à saúde e segurança do trabalhador, que são motivados pelos seguintes fatores: curta duração do contrato; quantidade reduzida de serviços contratuais e funcionários; falta das instalações básicas e das áreas de vivência; prática de subcontratação de mão-de-obra, provocando o trabalho informal; falta de EPI's e EPC`s; utilização de equipamentos ou ferramentas improvisados ou inadequados.

Atualmente, os órgãos governamentais para contratar obras e serviços de engenharia devem atender a Lei Federal 8.666/93, onde estabelece normas gerais sobre licitações e contratos administrativos no âmbito dos Poderes da União, dos Estados, do Distrito Federal e dos Municípios. Sendo uma Lei que estabelece normas, em seu artigo 12, incisos I e VI, trata sobre a Segurança do Trabalho. (Art. 12 Nos projetos[...] de obras e serviços serão considerados principalmente os seguintes requisitos:. I-Segurança; [..] VI - Adoção das normas técnicas, de saúde e de segurança do trabalho adequadas;).

Verifica-se que nas obras com pouca mobilização de mão-de-obra, não são observados os requisitos de segurança previsto nas Normas Regulamentadoras, especialmente, as especificações contidas na NR18 (Condições e Meio Ambiente de Trabalho na Indústria da Construção).

Isto ocorre devido a interpretação equivocada da Portaria 3214/78 do Ministério do Trabalho que especifica a obrigação da implantação do PCMAT
(Programa de Condições e Meio Ambiente de Trabalho na Indústria da Construção Civil) apenas para as obras que tenham mais de 20 funcionários.

Entretanto, a mesma Portaria determina que todo o empregador é obrigado elaborar e implantar o Programa de Controle Médico de Saúde Ocupacional (PCMSO-NR7) e o Programa de Prevenção de Riscos Ambientais (PPRA - NR9). Sendo assim, mesmo que não seja obrigatória a implantação do PCMAT, as empresas têm o dever independente do número de funcionários, implantar o PCMSO e PPRA, contemplando assim as medidas que garantam a saúde e integridade física de seus funcionários.

Com a desobrigação de se elaborar o PCMAT, deixa de existir os cuidados para se evitar os acidentes, através de medidas preventivas com levantamento dos riscos e doenças, execução/ instalações de equipamentos de proteção coletiva, treinamentos, etc. Assim, a quantidade de trabalhadores não justifica o não atendimento das NR's, tais como a NR-7 e NR-9, onde toda empresa deve implantar e, até mesmo a própria NR-18 também é descumprida, visto que o PCMAT é apena um item (18.3 da NR18), onde a mesma estabelece demais regras que devem ser seguidas.

Outro problema com o qual se depara é como prever os custos para implantar e manter as exigências das NR`s, de alguma maneira, esses custos devem estar considerados no orçamento da obra. Após a elaboração da planilha de custo da obra, a participante do certame deve dimensionar o BDI (Bonificação e Despesas Indiretas), que, em sua composição, estão os percentuais para cobrir os custos indiretos. No entanto, o Edital deve apresentar o valor máximo do BDI a ser adotado, devendo ser estipulado pelo órgão público licitante onde não é considerado a tipologia e as características da obra, fazendo com que os participantes do certame fiquem limitados para atender as exigências da legislação concernente as NR`s.

Finalmente, durante a execução das obras, a 
fiscalização é efetiva quanto à execução conforme o projeto e memorial descritivo, verificando a qualidade dos insumos e dos serviços realizados, deixando de lado a segurança e saúde ocupacional, motivado pela falta de profissional habilitado e cláusulas contratuais para exigir o cumprimento das NR`s. Diante de todo problema apresentado, e visto que os Editais da Prefeitura Municípal de Londrina, especificamente, mencionam de maneira superficial que as empresas devem atender as Normas do Ministério do Trabalho. (clausula terceira: [..] obedecendo aos requisitos de [...] E SEGURANÇA, previstos nas Normas do Ministério do Trabalho..), tem-se a necessidade de buscar os requisitos para a elaboração do Edital de licitação, que assegure o cumprimento da Lei de Licitações 8666/93 e das Normas Regulamentadoras, onde a elaboração do orçamento propicie verbas para o custeio da implantação e manutenção das NR's, e estabelecer no edital e no contrato, regras para a contratante e a contratada, indicando responsabilidades e penalidades, durante todo o período de vigência do contrato.

\section{Objetivo}

O objetivo deste trabalho é estabelecer critérios a serem observados no processo de elaboração de licitações para obras públicas, mesmo que mobilizem menos de 20 funcionários de modo a assegurar o cumprimento dos requisitos de segurança contidos nas Normas Regulamentadoras.

\section{Referencial Teórico}

Para um melhor entendimento sobre os pontos principais em que os editais devem ser elaborados, este tópico tratará dos seguintes temas:

- Legislação

- Leis Sociais

- BDI - (Bonificação e Despesas Indiretas)

- Subcontratações

\section{Legislação}

A ConstituiçãoFederalem seu artigo 37 determina que a Administração Pública deve obedecer os princípios de legalidade, impessoalidade, moralidade, publicidade e eficiência. E, segundo o inciso XXI, as obras deverão ser contratadas mediante processo de licitação pública.

Para regulamentar o artigo $37 \mathrm{da} \mathrm{CF}$, em 21/06/1933, entrou em vigor a Lei 8666, instituindo normas para as licitações, onde em seu artigo 12, incisos I e VI, nas obras deverão ser adotadas as normas técnicas, de saúde e de segurança do trabalho, indo de encontro com a Portaria 3214/78 do Ministério do Trabalho que regulamenta o artigo 200 do Decreto-Lei 5453/43, onde determina que toda empresa que possua empregados regidos por este decreto-lei (Consolidação das Leis do Trabalho - CLT) tem por obrigação observar as Normas Regulamentadoras.

Conforme art. 37, $\S 6^{\circ}$ da Constituição Federal e art. 927 do Código Civil, o Estado se responsabiliza pelos danos causados a terceiros numa obra pública, mesmo que por negligência exclusiva da construtora. Neste sentido, considerando ainda que realizar obra pública faz parte da atividade do Estado, o mesmo responde solidariamente ao construtor por descumprimento de norma de segurança no trabalho perante o empregado da construtora por ele contratada.

Considerando a Súmula $\mathrm{n}^{\circ} 331$ do TST no item IV (IV-O inadimplemento das obrigações trabalhistas, por parte do empregador, implica a responsabilidade subsidiária do tomador dos serviços, quanto àquelas obrigações, inclusive quanto aos órgãos da administração direta [...] desde que hajam participado da relação processual e constem também do título executivo judicial), entra em conflito a Lei 8666/93, no art $71, \S$ 1o (O contratado é responsável pelos encargos trabalhistas, [...] resultantesdaexecuçãodocontrato. A inadimplência do contratado, com referência aos encargos trabalhistas, [...] não transfere à 
Administração Pública a responsabilidade por seu pagamento, nem poderá onerar o objeto do contrato ou restringir a regularização e o uso das obras e edificações, inclusive perante o Registro de Imóveis), onde existem duas linhas de pensamentos e como a questão surgiu com a Ação Direta de Constitucionalidade - ADC n ${ }^{\circ} 16 / 2007$, e o TST rejeitou recurso com base na decisão do STF (AIRR3138/2006), a Justiça do Trabalho tem aplicado normalmente o item IV da Súmula 331 do TST.

\section{Leis Sociais}

A planilha de orçamentos é composta por relação de serviços, com suas respectivas quantidades e custo unitário, onde a somatória dos serviços se obtém o custo total de uma obra. $\mathrm{O}$ custo do serviço pode ser composto por custos referente à mãode-obra, materiais e equipamentos. Na parcela de mão-de-obra está incluso as despesas para as Leis Sociais, que servem para remunerar o pagamento das despesas legais, como Previdência Social, repouso semanal, férias, $13^{\circ}$ salário, Fundo de Garantia por Tempo de Serviço (FGTS), transporte, alimentação, SESI, SENAI, entre outros.(TCPO 10-PINI).

\section{$B D I$}

Nas licitações públicas, o valor do BDI deve ser estipulado pela Administração Pública. Conforme definição pelo Tribunal de Contas da União (acórdão 325/2007), o BDI é "um percentual aplicado sobre o custo para chegar ao preço de venda a ser apresentado ao cliente", onde existem parcelas comuns para todos os participantes do certame como impostos, e outros são distintos para cada empresa, como o rateio da administração central, seguros, riscos.

$\mathrm{O}$ valor do BDI considerado pela Prefeitura do Município de Londrina é de $25 \%$, mas não há detalhamento do mesmo, visto que a porcentagem foi definida através de consulta em diversos editais.
No entanto, as obras onde a Caixa Econômica Federal está gerenciando a conta de repasse de verbas federais, a composição do BDI deve estar dentro dos limites estipulados conforme indicado na tabela 1 .

Tabela 1. Composição de BDI - CEF

\begin{tabular}{lccc}
\hline & Mínimo & Médio & Máximo \\
\hline 1. Administração & & & \\
Central & $0,11 \%$ & $4,07 \%$ & $8,03 \%$ \\
2. Garantia & $0,00 \%$ & $0,21 \%$ & $0,42 \%$ \\
3. Despesa & & & \\
financeira & $0,00 \%$ & $0,59 \%$ & $1,20 \%$ \\
4. Riscos & $0,00 \%$ & $0,97 \%$ & $2,05 \%$ \\
5. Tributos & $6,03 \%$ & $7,65 \%$ & $9,03 \%$ \\
6. Lucro & $3,83 \%$ & $6,90 \%$ & $9,96 \%$ \\
\hline Total & $10,61 \%$ & $22,61 \%$ & $35,41 \%$ \\
\hline
\end{tabular}

O TCU (Tribunal de Contas da União acórdão 325/2007) determina que os custos para a administração local do canteiro devem estar discriminados na planilha orçamentária. São considerados custos da administração local, a mãode-obra indireta, a mobilização e desmobilização do canteiro, a vigilância, ferramentas e equipamentos de pequeno porte, a operação do programa de segurança e saúde do trabalho.

\section{Subcontratação}

A subcontratação é tratada na Lei 8666 conforme os artigos 72 e 78 inciso VI.

Art. 72. O contratado, na execução do contrato, sem prejuízo das responsabilidades contratuais e legais, poderá subcontratar partes da obra, serviço ou fornecimento, até o limite admitido, em cada caso, pela Administração.

Art. 78. Constituem motivo para rescisão do contrato: 
[...] VI - a subcontratação total ou parcial do seu objeto, a associação do contratado com outrem, a cessão ou transferência, total ou parcial, bem como a fusão, cisão ou incorporação, não admitidas no edital e no contrato;

$\mathrm{O}$ artigo 72 refere-se a possibilidade da subcontratação em partes da obra conforme o limite admitido pela administração. No entanto, o inciso VI do artigo 78 relata a rescisão do contrato para a subcontratação total ou parcial não admitida no edital.

Portanto, a prática da subcontratação, parcial ou total, somente poderá ocasionar a rescisão contratual se o mesmo não observar o edital e contrato.

\section{Método}

Através de pesquisa pela internet, em diversos editais e minutas de contrato de serviços de engenharia para obras públicas, obteve-se 17 editais de governo municipal, estadual e federal, órgãos e empresas públicas. $\mathrm{O}$ edital utilizado como base de comparação foi o edital do município de Londrina/ PR, da obra Implantação da Praça da Juventude Região Sul.

Com o intuito de atender o objetivo proposto neste trabalho, a análise dos contratos e editais foi apenas quanto ao Programa de Saúde Ocupacional, verificando exigências, responsabilidades, penalidades e rescisões contratuais, conforme segue:

- Orçamento;

- Obrigações da Contratada;

- Obrigações da Contratante;

- Documentos para início da obra, medições parciais e entrega final da obra;

- Penalidades e Rescisão.

Com os dados obtidos e tabulados, foram elaboradas diretrizes para atingir o objetivo deste trabalho, conforme segue:

- Durante a elaboração do orçamento da obra e no preparo da licitação, considerando o porte e característica da obra, garantir e demonstrar a verba para o programa de saúde e segurança do trabalho;

- Não permitir que seja utilizada mão-de-obra informal, garantindo assim os direitos trabalhistas e eliminar a sonegação fiscal, principalmente ao INSS;

- Propor a inclusão de cláusulas contratuais para garantir a efetiva execução do programa, indicando as responsabilidades e penalidades;

- Melhorar as condições ambientais aos trabalhadores e, como conseqüência, propor condições para possibilitar a melhoria na qualidade da mão-de-obra, motivado pela higiene e organização;

- Propor orientações para o fiscal de obra de como efetuar a fiscalização, quanto à saúde e segurança do trabalho, fazendo que o gerenciamento da qualidade seja somado ao programa de saúde e segurança ocupacional; e

- Minimizar o risco de mortes, acidentes ou doenças do trabalho, onde a contratante (Administração Pública) tem responsabilidade solidária, conforme a legislação vigente (art. 37, $\S 6^{\circ}$ da Constituição Federal e art. 927 do Código Civil).

\section{Tratamento dos Dados}

Nas entrevistas realizadas nos canteiros de obras públicas, verificou-se que a prática da subcontratação de mão-de-obra é largamente utilizada. No entanto, o profissional ao sair da empresa que o contratou, poderá comparecer na Delegacia Regional do Trabalho, ou Sindicato para requerer seus direitos trabalhistas e previdenciários.

De modo geral, as obras licitadas atualmente em Londrina, por se tratarem de obras de construções e 
reformas, com duração de até 6 meses, permite que a empresa contratada mobilize a mão-de-obra no canteiro de obras de maneira que não seja necessária a elaboração do PCMAT. Entretanto, deve-se destacar que independente da quantidade de trabalhadores, toda empresa que possui empregado contratado e regido pela Consolidação das Leis do Trabalho é obrigada observar as normas regulamentadoras.

Para as obras que necessitem de mobilização maior de mão-de-obra, no decorrer do contrato, a Contratada se utiliza do expediente de aditivo contratual para a renovação do prazo de execução, com argumentações por falta de projetos, acréscimos de serviços, entre outros. Devido as exigências da Lei 8666/93, os termos devem ser justificados e substanciados, com a demora da contratada em solicitar o aditivo, adquire um tempo maior.

Sobre a não utilização dos EPI's, as desculpas são variadas. Nas entrevistas, informaram que a empresa não fornece os EPI's ou os mesmos causam incômodo durante a realização do trabalho, prejudicando a agilidade e produtividade, e que ao longo dos anos de trabalho tem-se hábito de mão usar os EPI.

Um profissional com larga experiência profissional em sua atividade pode deixá-lo facilmente exposto aos acidentes, pois a falta de cuidados e a atenção, mesmo nas atividades mais corriqueiras, são os principais motivos dos acidentes, doenças e mortes pelo trabalho laboral.

Conforme as NR's, o uso dos EPI's deve ser a última opção para a proteção do trabalhador, onde ao ser detectado o risco, primeiro deve-se tentar eliminar o gerador do mesmo, ou fazer que fique dentro dos limites especificados, onde não sendo possível, deve-se utilizar dos EPC's e, ainda não sendo o suficiente, por último utiliza-se dos EPI`s.

A falta de cláusulas contratuais que especifiquem claramente o programa de segurança e saúde do trabalhado, faz que as contratadas se utilizem diretamente de alguns EPI's, que geralmente são capacetes e botas, e sem a devida preocupação do tipo e uso correto para cada atividade.

A subcontratação na obra pública está prevista na Lei 8666 e só pode ser efetivada com a autorização da administração pública, no entanto, "podem" trazer prejuízo à administração, conforme segue:

- Falta de comprometimento para cumprir o cronograma físico, ocasionando atraso;

- Mão-de-obra de baixa qualidade (para aumentar o lucro da contratada);

-Conflitos entre as etapas da obra, permitindo que um determinado serviço seja realizado sem a conclusão do serviço anterior;

- Serviço realizado com má qualidade, deixando problemas para as etapas seguintes;

- Prejuízo devido aos serviços executados fora de conformidade; e

- Dificuldades para a fiscalização verificar quanto às responsabilidades, entre outros.

Neste mesmo enfoque, para a fiscalização do órgão público, nota-se a falta de infra-estrutura e o grande número de obras onde o acúmulo de tarefas dificulta o trabalho do fiscal, fazendo que compareça na obra de maneira irregular e muito rápida. A falta de treinamento das equipes do órgão público nos setores de projetos, orçamentos e fiscalização, deixa a administração pública à mercê das conseqüências geradas pelos acidentes do trabalho, morte e doenças ocupacionais, com intimações judiciais de funcionários contra as empresas contratadas, onde a administração pública é solidária e regressiva por desrespeito à legislação trabalhista.

Quanto às condições ambientais de trabalho a situação é muito crítica, principalmente a falta de local apropriado para as refeições, não haver chuveiros e a existência de sanitários improvisados. De posse dos 17 editais (relacionados na referência bibliográfica), efetuou-se a compilação dos itens referentes ao tema deste artigo, onde seguem as análises: 


\section{Estudo na formulação do BDI}

Conforme o acórdão TCU $n^{\circ} 325-2007$, não podem ser considerados como Custo Indireto, a administração local da obra, e todos os custos, mesmo não pertencentes ao objeto final da obra, devem ser relacionados na planilha de orçamento. Sabe-se que a administração local absorve os custos para a manutenção da mão-de-obra indireta (administrativa e técnica) juntamente com as despesas para o andamento da obra.

As despesas para a elaboração do programa de saúde ocupacional (SESMT, LTCAT, PPP, PPRA, PCMSO e PCMAT) podem ser consideradas dentro da parcela do BDI correspondente à "Administração Central". Aefetivação do programa, como os espaços de convivência, refeitórios, sanitários e EPC's, entre outros, devem ser considerados na "Administração Local", onde deverá estar relacionado na planilha orçamentária. Os custos para o fornecimento dos EPI’s deve fazer parte da composição das Leis Sociais.

A composição apresentada pela Prefeitura de Londrina à CEF/REDUR atende a solicitação do TCU, não considerando a administração local, onde foi composta conforme a tabela2.

Tabela 2. Composição de BDI - CEF

\begin{tabular}{lc}
\hline Composição & \% \\
\hline 1. Administração Central & $5,45 \%$ \\
2. Garantia & $0,31 \%$ \\
3. Despesa financeira & $0,69 \%$ \\
4. Riscos & $0,97 \%$ \\
5. Tributos & $7,65 \%$ \\
6. Lucro & $7,35 \%$ \\
\hline Total & $25,00 \%$ \\
\hline
\end{tabular}

No entanto, a planilha orçamentária em análise, para o custeio da "Administração Local", contém somente o Abrigo Provisório de Obra, com área estimada em $20 \mathrm{~m}^{2}$. Sabe-se que a área estimada não é o suficiente para abrigar todas as necessidades da obra, como sanitários, refeitório, depósito, almoxarifado, escritório, vestiário. Ficaram de fora da planilha os custos da mão-de-obra indireta e da manutenção dos EPC`s (guarda-corpo, passarelas, telas de proteção, etc). Desta maneira, a manutenção do canteiro de obras e do programa de segurança está comprometida pela falta de provisão de recursos no orçamento.

\section{Obrigações da contratada}

$\mathrm{Na}$ maioria dos editais (13 unidades) estabelecem que as obrigações das contratadas principalmente são referentes aos encargos e obrigações trabalhistas, de fazer cumprir as NR`s e fornecer e fazer usar os EPI's.

Nos demais editais (3 unidades) as indicações das responsabilidades são bem mais amplas, solicita apresentar de certidões negativas de débitos e de comprovantes de quitação dos encargos sociais, atender as normas regulamentadoras, fornecer EPI`s, efetuar treinamento de formação básica de segurança na construção civil, afastar funcionários insubordinados, efetuar sinalização na obra, apresentar relatórios de acidentes e de gerenciamento de riscos, elaborar e apresentar o PCMSO e o PPRA.

\section{Obrigações da contratante}

As obrigações da contratante se baseiam na fiscalização durante a realização dos serviços, efetuar a medição e providenciar o pagamento; relatar no diário de obras os fatos ocorridos de maneira geral; efetuar a retenção de $11 \%$ para a contribuição previdenciária.

Fato que chamou a atenção que entre os editais analisados, um edital determina que o fiscal tem a obrigação de solicitar a paralisação dos serviços caso seja constatado a falta de segurança.

Para as obrigações de responsabilidade civil em geral, sabe-se que o município responde conforme já 
mencionado.

\section{Documentos para o Início de Obra}

A liberação para início das obras é condicionada à emissão da Ordem de Serviço que está vinculado ao contrato e ao Empenho. Não se exige nenhuma documentação complementar para o início das obras, a não ser para a conclusão da obra, onde o Termo de Recebimento está vinculado a apresentação dos Alvarás, ART-CREA, e Certidões do INSS.

Entretanto, dois editais chamaram atenção pelas exigências de documentações que devem ser apresentados no início da obra, o PPRA, PCMSO, matricula no INSS, comprovante da comunicação ao INSS do início da obra, curso sobre segurança do trabalho.

\section{Documentos para Medições e Pagamento}

Nos editais da prefeitura de londrina, as medições e os pagamentos devem ser protocolados pela Contratada, e anexados com a planilha de medição, a declaração de que a empresa possui regularidade contábil e Certidão Negativa de Débitos - CND do INSS. A apresentação da certidão negativa de débitos do INSS e a verificação da validade da mesma pelo setor de contabilidade, não garante que os funcionários estão efetivamente registrados e que a Contratada está cumprindo com as obrigações.

Dos editais analisados verificou-se que em 3 licitações as condições para a apresentação das medições e pagamentos são mais restritivas, devido a necessidade de apresentar comprovantes e guias de pagamentos, tais como: relação de funcionários e cópia de recibo de pagamento dos mesmos, apólice de seguro para acidentes do trabalho, de terceiros e da obra propriamente dita, entre outros. Desta maneira os documentos entre si se completam, fazendo que um determinado documento seja comprovante de outro.

\section{Documentos para entrega final}

A entrega final da obra é solicitada após a emissão do Termo de Recebimento Provisório, onde a prefeitura constituirá uma comissão para vistoriar a obra e averiguar o atendimento aos termos do contrato. Constatado o seu total cumprimento, emitese o Termo de Recebimento Definitivo.

Desta maneira, conforme estipulado em contrato, não existe nenhuma verificação quanto ao atendimento pela Contratada às obrigações, muito menos a apresentação de documentação comprovando a quitação dos débitos gerados no decorrer da obra.

Para a devolução do seguro caução, caso a contratada não opte pelo seguro-garantia, é solicitado somente a CND do INSS da referida obra que novamente não garante os direitos trabalhistas dos funcionários da referida obra.

Para os editais analisados, verifica-se que, aqueles mais completos e detalhados, a exigência para a entrega da obra solicita a Certidão do INSS que está embasada numa documentação complementar no decorrer da obra.

Nota-se que a garantia os diretos trabalhistas e uma maior eficácia no programa de segurança e saúde ocupacional não está relacionada somente na CND do INSS, mas num conjunto de ações que levam a concretização do seguro previdenciário e trabalhista e principalmente na proteção do trabalhador em suas atividades laborais.

\section{Penalidades e rescisão contratual}

A penalidade e rescisão contratual nos editais analisados, inclusive o referenciado, resumese ao não cumprimento dos termos contratuais. Considerando que apenas 3 editais se preocupam com o PCMSO, as penalidades também se reportam ao não cumprimento das NR's.

\section{Subcontratação}

Uma situação importante verificada em todos 
os editais é a subcontratação dos serviços, onde 2 editais proíbem e os demais permitem até $30 \%$ do contrato. No entanto, nada é mencionado sobre em que condição se dará a subcontratação e quais as documentações necessárias. Para esses editais, menciona-se apenas que a subcontratação deverá ser autorizada pela fiscalização por escrito.

Verifica-se que este expediente de subcontratação de serviços é muito utilizado, conforme verificado com a fiscalização do Ministério do Trabalho, através de empreitadas com pessoas físicas ou até mesmo com pequenas empresas, onde se utilizam de mão-deobra temporária sem nenhuma preocupação quanto a legislação trabalhista.

Não se pode esquecer também das empresas que executam serviços especializados terceirizados como fornecimento e instalação de calhas, rufos, pedras de granito, vidros, serralheria, entre outros, que são largamente utilizados.

\section{Discussões e orientações}

Verificado a grande diversidade entre nos editais analisados, onde três contratos propõem várias cláusulas para garantir o perfeito funcionamento do programa de saúde e segurança ocupacional, e os demais de maneira mais simples apresentando cláusulas genéricas. Sabe-se que quanto mais o contrato conter exigências, maior será a demanda para a fiscalização. Contudo, deve-se considerar que, mesmo com o aumento da demanda é devido tomar todos os cuidados para garantir e atender as exigências Legais. Neste enfoque, seguem orientações para a elaboração dos orçamentos, a inclusão de cláusulas contratuais nos editais e diretrizes para a fiscalização em todo o processo, durante a vigência do contrato.

\section{BDI - Orçamentos}

Considerando o acórdão do TCU, o orçamento deve contemplar o custo para a Administração Local, onde neste custo deverá considerar os EPC`s e toda a infra-estrutura necessária para a realização dos serviços de engenharia.

Portanto, os custos relacionados a "manutenção" do programa de segurança e saúde do trabalho deverá estar contemplado na planilha orçamentária.

A composição do BDI deverá ser detalhada para cada tipo de obra, conforme as características, porte, etc.. onde as taxas devem ser dispostas para atender as necessidades para a implantação do programa de segurança e saúde do trabalho. A segregação do Programa de Saúde e Segurança do Trabalho do item "Administração Central" tem por finalidade indicar a existência da verba necessária para a implantação do PCMSO.

Para o custeio do fornecimento dos EPI’s, deverá ser considerado nas Leis Sociais, conforme já adotado.

Sabe-se que devido a característica da obra, as porcentagens de cada item que compõe o BDI são variáveis em si e que não necessariamente chegam ao mesmo valor final.

A proposta do acórdão do TCU impõe um orçamento mais elaborado quanto à mobilização, desmobilização e a manutenção do canteiro.

Neste sentido, segue uma nova proposta, conforme a tabela 3 para o cálculo do BDI.

Tabela 3. Nova proposta de composição de BDI

\begin{tabular}{lccc}
\hline Descrição & Obra & Obra & Obra \\
& tipo 1 & tipo 2 & tipo "n" \\
\hline
\end{tabular}

1. Administração Central

\section{Progr. Seg. Trab.}

3. Risco

4. Garantia/Seguros

5. Despesas Financeiras

6. Tributos

7. Lucro

\section{Total}


Garantido no orçamento o Programa de Saúde e Segurança do Trabalho, o edital de licitação e a minuta do contrato devem indicar as obrigações, a apresentação dos documentos que comprovem ao atendimento conforme solicitado pelo contrato, e as penalidades no caso de não cumprimento do contrato.

\section{Início de obra}

Considerando que após o Recebimento da Ordem de Serviço a Contratada tem 5 dias para iniciar a obra, primeiramente a Contratada deve apresentar os seguintes documentos:

- Matrícula da Obra no INSS- CEI;

- Apólice de Seguro para morte ou invalidez permanente conforme o número de trabalhadores na GFIP e funcionários da Contratada (quantidade de funcionários que trabalham no local da obra e os que fiscalizam a obra em questão);

- Apólice de seguro para responsabilidade civil e propriedades;

- Relação dos funcionários que serão lotados na referida obra;

- Cópia das Carteiras de Trabalho e Previdência Social de todos os funcionários. Poderá solicitar a comprovação do tempo de experiência mínimo;

- Apresentar o SESMT, LTCAT, PCMSO, PPRA, PPP;

- Apresentar o PCMAT - NR18 (para obra com mais de 20 funcionários);

- Apresentar ASO (Atestado de Saúde Ocupacional);

- Relação dos funcionários que trabalharão com energia elétrica e apresentar certificado do curso NR10;

- Comprovação de curso de segurança admissional com duração mínima de 6 horas, conforme NR18;
- Ordem de Serviço sobre Segurança e Medicina do Trabalho, conforme NR1;

Os documentos acima relacionados vão garantir o registro dos funcionários e a implantação do PCMSO.

\section{Durante a Execução da Obra}

No decorrer da obra, a Contratada também tem como obrigação:

- Fornecer e fazer usar os EPI's;

- Disponibilizar desde o início da obra, sanitários, chuveiros, local para refeições e demais exigências conforme NR18;

- Todos os funcionários deverão estar uniformizados e identificados, inclusive os subcontratados e os de serviços terceirizados;

- Em caso de acidente, avisar a fiscalização e entregar a CAT elaborado pelo SESMT;

- Em caso de Acidente grave ou morte avisar imediatamente a fiscalização;

- Manter o diário de obras atualizado que deverá ser constituído em 3 vias (bloco, contratada e fiscalização/medição)

Durante a execução da obra tem-se a importância da verificação pela permanência do programa, não deixando que logo após o início das obras, as etapas seguintes sejam abandonadas. Além do dever que a fiscalização tem de verificar o andamento dos serviços, deve-se utilizar da oportunidade para solicitar e verificar os documentos que comprovem a manutenção do programa.

\section{Medição de Obra}

Para a efetivação das medições periódicas da obra, o Contratante deve se utilizar deste precedente para solicitar os recibos e certidões que comprovem o perfeito atendimento das exigências do contrato quanto à legislação trabalhista e segurança do 
trabalho, que são:

- Relatório de Segurança e Medicina do Trabalho, informando o número de funcionários, número de acidentes, dias parados ou perdidos, cursos e treinamentos, inspeções de segurança, e fornecimento de EPI`s;

- Declaração do empregador, ou responsável pela gestão ou direção da empresa, dando conta da regular quitação de todos os direitos sociais trabalhistas de seus empregados;

- Certidão Negativa de Débito do INSS;

- CRF (Certificado de Regularidade do FGTS);

- Demonstrativo de Dados Referente ao FGTS;

- Guia de Previdência Social (GPS) - GRPS de conformidade com o "Demonstrativo de Dados Referente ao FGTS" - devidamente quitada;

- Guia de Recolhimento do FGTS e Informações à Previdência Social - GFIP, devidamente quitada;

- Guia de Recolhimento do PIS (Programa de Integração Social);

- GPS por matrícula - CEI;

- Relação dos funcionários envolvidos do objeto do contrato no período, constante no arquivo SEFIP;

- Cópia do livro/cartão de ponto, folha de pagamento de salário, entrega de vale transporte, e vale alimentação dos empregados envolvidos na execução do objeto contratado; e

- Recibos e quitações do seguro da obra, terceiros e acidentes de trabalho.

As cópias deverão ser autenticadas em cartório ou por funcionário do Contratante.

\section{Encerramento da Obra}

No encerramento da obra, antes da emissão do Termo de Recebimento Definitivo, a Contratada deve apresentar a documentação final para o encerramento do contrato, que são:
- Certidão Negativa de Débito da Obra - INSS;

- Documentação para o encerramento do contrato; e

-Diário de Obras

Para os contratos que se permite a subcontratação, as solicitações de documentações também devem ser reportadas para estas empresas, para se garantir que todos os trabalhadores envolvidos fiquem na mesma condição dos trabalhadores da contratada. Além do mais, durante a elaboração de uma licitação de obra pública, não se prevê alguma condição diferente para a atuação de subcontratação e serviços especializados de terceiros.

No decorrer da obra, as obrigações da contratante e contratada se complementam entre si. A Contratada deve executar os serviços contratuais conforme as normas e especificações e a contratante cabe fiscalizar efetuar o pagamento do serviço realizado. Na mesma direção, a contratada deve obedecer as leis trabalhistas e a contratante efetuar a fiscalização do real cumprimento.

\section{Obrigações da Contratada}

Para o contratado, têm-se as seguintes obrigações:

-Pagamento dos encargos trabalhistas;

-Apresentar certidões quando solicitado pela contratante;

-Fazer cumprir as NR`s;

-Retirar da obra os funcionários negligentes, insubordinados, imprudentes ou que não submeterem a utilizar os EPI's e atender ao PCMSO;

- Anotar no diário de obras, as ocorrências de Segurança e Saúde Ocupacional;

-Efetuar subcontratação somente com autorização formal da contratante; e

-Solicitar da subcontratada os documentos comprobatórios quanto ao PCMSO. 


\section{Obrigações da Contratante}

A contratante na pessoa do fiscal tem as seguintes responsabilidades:

- Fiscalizar o cumprimento do programa de saúde e segurança ocupacional;

- Providenciar a paralisação das atividades que ofereçam risco ao trabalhador e/ou pessoas próximas do local, sem prejuízo ao cronograma físico-financeiro da obra;

- Solicitar substituição de funcionários que não atendam o programa de saúde e segurança ocupacional;

- Anotar as ocorrências no diário de obras; e

- Comunicar ao gestor de contratos as irregularidades.

\section{Penalidades para a Contratada}

$\mathrm{Na}$ eventualidade que a contratada não cumprir os termos do contrato, torna-se a necessidade de se efetuar as penalidades. Para a contratada tem-se:

- Multa por não apresentar os documentos solicitados;

-Multa por não cumprir o programa de saúde e segurança ocupacional;

Conforme a gravidade ou a reincidências dos fatos além das penalidades, a contratada poderá sofrer a rescisão contratual onde poderá apresentar sua defesa conforme previsto na Lei 8666/93.

\section{Penalidades para a Contratante}

$\mathrm{Na}$ eventualidade que a contratante na pessoa do fiscal em não cumprir os termos do contrato, tornase a necessidade de se efetuar as penalidades, temse:

- Advertência por não atender os termos do contrato.

- Se o funcionário público, na pessoa do fiscal, deixar de exigir o previsto em contrato, ciente de que é sua obrigação em fazê-lo, responderá civil, penal e administrativamente.

\section{Diretrizes e orientações para a fiscalização}

A grande dificuldade do órgão público é a falta de técnicos com o conhecimento na área de Segurança do Trabalho. A atuação da fiscalização enfocada apenas na qualidade dos serviços, e a falta de cláusulas contratuais sobre Segurança do Trabalho, faz que o programa de segurança e saúde do trabalho seja passível de não ser efetivado. Ideal é que o órgão público tenha um profissional exclusivo para fiscalizar as obras, não importando suas características, desde uma pequena manutenção ou reforma até uma obra de grande porte. Na falta deste profissional, tem-se a necessidade de se elaborar uma especificação para uso da fiscalização, pó exemplo, um check-list, de maneira que, mesmo sem um conhecimento aprofundado sobre a segurança do trabalho, o fiscal tenha condições de verificar os itens de segurança, onde se destaca:

- Número de empregados

- Existência de SESMT, LTCAT, PCMSO, PPRA, PPP e PCMAT.

- Local de vivência - refeitório, sanitários

- Cuidados em escavações, devido à instabilidade de terra e perigo com quedas

- Proteção em Equipamentos e bancadas

- Escadas, rampas e passarelas

- Trabalho em altura

- Transporte de materiais e pessoas

- Andaimes

- Instalação elétrica - curso NR10 para os profissionais que trabalham neste setor

-EPI`s, EPC`s, sinalização

- Limpeza e higiene no ambiente de trabalho 
-Documentação - diário de obras, certidões, cursos e treinamentos

\section{Conclusão}

Diante do exposto, verifica-se a que o órgão público deve tomar todos os cuidados durante o processo licitatório, desde a elaboração do orçamento, edital, contrato e finalizando pelo Termo de Recebimento Definitivo, para garantir que a legislação seja cumprida em sua integridade.

Enfim, tem-se a expectativa para que este trabalhado contribua na melhoria da execução das obras públicas, considerando:

- A efetivação do cumprimento das NR's normas regulamentadoras;

- A valorização do trabalhador com remuneração e inclusão dos direitos trabalhistas conforme CLT e INSS, a saúde e a segurança ocupacional;

-Indiretamente, melhorar a qualidade da mãode-obra, motivada pela higiene do meio ambiente, a saúde e segurança dos trabalhadores;

- Atendimento da legislação vigente e a eliminação da sonegação fiscal;

- Execução das obras em conformidade com as especificações e as normas técnicas da ABNT;

- Aumento da vida útil da obra e ao seu desempenho de modo geral, adiando a necessidade de efetuar reparos e consertos devido a não conformidade;

- Orientações para a atuação da fiscalização, melhorando a técnica das vistorias, unindo a qualidade com a segurança; e

- Padronização de documentação, facilitando a consulta, verificação, e auditoria.

Portanto, considerando a observação das etapas relacionadas neste trabalho, o Programa de Saúde Ocupacional do Trabalho terá seus objetivos atendidos na sua totalidade, com a utilização de diretrizes para a elaboração do orçamento, licitação, fiscalização e recebimento do objeto do contrato.

Os temas não tratados neste artigo, como a variação dos percentuais do BDI e Leis Sociais, a especificação de serviços para a fiscalização, poderão auxiliar para a melhoria na qualidade da obra.

\section{Discussões futuras}

- Determinação dos percentuais dos itens que compõe o BDI para obras conforme as características, adequando as parcelas de maneira realista, principalmente para o programa de saúde e segurança ocupacional;

- Estudo regionalizado para a composição das leis sociais, devido aos acordos sindicais;

- Elaboração de especificação para fiscalização quanto à segurança do trabalho;

- Estudo de meios para minimizar os riscos de acidentes durante os serviços de manutenção em edifícios públicos;

\section{Referências}

APUCARANA. Prefeitura Municipal. Edital de tomada de preços $n^{o}$ 04/10. Disponível em: <http://www. apucarana.gov.br>. Acesso em: 29 mar. 2010.

BRASIL. Lei $n^{\circ}$ 8.666, de 21 de junho de 1993. Disponível em: <http://www.planalto.gov.br/ccivil_03/ Leis/L8666cons.htm>. Acesso em: 20 maio 2010.

Ministerio do Trabalho. Edital pregão eletrônico $n .{ }^{\circ} 12$ / 2010 - SRP. Disponível em: <http://www.mte.gov.br/ editais/pregoes_2010.asp >. Acesso em: 1 jun. 2010.

CASCAVEL. Prefeitura Municipal. Edital tomada de preços n $n^{\circ} 33 / 2010$. Disponível em: <http://www.cascavel. pr.gov.br/>. Acesso em: 10 maio 2010.

COMPANHIA DE HABITAÇÃO DE LONDRINA. Edital de concorrência $C P n^{\circ}$ 003/2009. Disponível em: $<$ http://www.cohabld.com.br>. Acesso em: 5 jan. 2010.

COMPANHIA DE SANEAMENTO DO PARANÁ. Edital concorrência pública $n^{\circ}$ 412/2009. Disponível em: <http://www.sanepar.com.br>. Acesso em: 29 mar. 2010. 
CONSELHO NACIONAL DE PREVIDÊNCIA SOCIAL. Resolução $n .^{\circ}$ 1.316, de 31 de maio de 2010. Disponível em: $<$ http://www2.dataprev.gov.br/fap/ resolucao1316.pdf $>$

CURITIBA. Prefeitura Municipal. Edital de concorrência $n^{\circ}$ CI/002/2010-SMOP/OPP. Disponível em: <http:// www.curitiba.pr.gov.br>. Acesso em: 29 mar. 2010.

DRAGONI, José Fausto. Segurança, saúde e meio ambiente em obras. São Paulo: LTR, 2006.

FREIRES, Alecio Pinheiro; PAMPLONA, Edson de Oliveira. Um foque no BDI de Empresas Construtoras de Pequeno Porte com a utilização das ferramentas de custeio ABC/ABM. In: CONGRESSO INTERNACIONAL DE CUSTOS, 9., 2005, Florianópolis. Anais... Florianópolis: Universidade Federal de Itajubé, Itajubé.

INSTITUTO BRASILEIRO DE ENGENHARIA DE CUSTOS. Orientação técnica $n^{\circ}$ 1/2009/IBEC: conceito de BDI. Disponível em: <http://www.ibec.org.br>. Acesso em: 20 abr. 2010.

JOINVILE. Prefeitura Municipal. Edital de tomada de preços $n^{\circ}$ 018/2010. Disponível em: <http://www. joinville.sc.gov.br/>. Acesso em: 29 mar. 2010.

LONDRINA. Prefeitura Municipal. Edital tomada de preços CP/SMGP0012/2010. Disponível em: <http:// www.londrina.pr.gov.br/>. Acesso em: 3 maio 2010.

MARINGÁ. Prefeitura Municipal. Edital tomada de preços $n^{\circ}$. 012/2010-PMM. Disponível em: <http://www. maringa.pr.gov.br/>. Acesso em: 29 mar. 2010.

\section{MINISTÉRIO DO TRABALHO E EMPREGO.} Normas Regulamentadoras NR1 à NR33. Disponível $\mathrm{em}: \quad<\mathrm{http}: / /$ portal.mte.gov.br/legislacao/normasregulamentadoras-1.htm >. Acesso em: 3 jun. 2009.

NOGUEIRA, Carnot Leal. Auditoria de qualidade de obras públicas. São Paulo: Pini, 2008.

OLIVERIA, Cláudio Antonio Dias de. Aplicando os procedimentos técnicos em segurança e saúde no trabalho na área da construção. São Paulo: LTR, 2005.

PINHAIS. Prefeitura Municipal. Edital concorrência pública $n^{\circ}$ 008/2010. Disponível em: <http://www. pinhais.pr.gov.br/>. Acesso em: 13 maio 2010.

PORTO ALEGRE. Prefeitura Municipal. Edital concorrência pública $\mathrm{n}^{\circ}$ 02.081024.09.6. Disponível em: $<\mathrm{http} / / /$ www.portoalegre.rs.gov.br/smov/>. Acesso em: 29 mar. 2010.

ROCHA, Márcio Soares da. Análise de BDI de obras públicas pelo método da estimativa intervalar. Disponível em: $\quad<$ http://www.ibraop.org.br/site/media/sinaop/10 sinaop/>. Acesso em: 20 maio 2010.
SÃO PAULO. Prefeitura Municipal. Convite $n^{\circ}$ 034/ EDIF/SIURB/09. Disponível em: $<$ http://www.prefeitura. sp.gov.br>. Acesso em: 31 mar. 2010.

TRIBUNAL DE CONTAS DA UNIÃO. Acórdão 3252007. Critério para aceite do LDI. Disponível em: $<$ http:// www.tcu.gov.br>. Acesso em: 29 mar. 2010.

TRIBUNAL DE JUTIÇA DO ESTADO DO PARANÁ. Convite $n^{\circ}$ 07/2010. Disponível em: <https://portal.tjpr. jus.br/web/dp/compras_licitacoes $>$. Acesso em: 2 mar. 2010

TRIBUNAL REGIONAL DO TRABALHO. Pregão 032/2010. Disponível em: <http://www.trt9.jus.br>. Acesso em: 28 maio 2010.

TP164/2009. Disponível em: <http://www.trt2. $\overline{\text { gov.br> }}$. Acesso em: 2 jun. 2010.

Recebido em 1 Maio 2011-Received on May 1, 2011.

Aceito em 31 Agosto, 2011 - Accepted on August 31, 2011. 